\title{
Effect of use of direct observation of procedural skills for assessmentfor learning in Obstetrics and Gynaecology postgraduate students at Medical University, Bhutan: a prospective study
}

\author{
${ }^{1}$ Faculty of Postgraduate Medicine, KGUMSB, Thimphu, Bhutan \\ ${ }^{2-4}$ Jigme Dorji Wangchuck National Referral Hospital, Thimphu, Bhutan \\ ${ }^{5,6}$ GS Medical College, Mumbai, India
}

Karma Tenzin ${ }^{1}$, Sonam Gyamtsho², Tshering Wangdon ${ }^{3}$, Pema C. Buttia ${ }^{4}$, Lalitha Chandans ${ }^{5}$, Nirmala Rege ${ }^{6}$

\begin{abstract}
Introduction: Direct Observation of Procedural Skills (DOPS) is a valuable method to evaluate procedural skills. The aim of this study was to explore the effect of DOPS as an assessment method and its effect on their learning in Obstetrics and Gynecology Postgraduate students. Methods: Five residents and four faculty members from the department of Obstetrics and Gynecology, Khesar Gyalpo University of Medical Sciences of Bhutan participated in this study. A validated checklist was adopted, from which five core areas of DOPS were utilized for this study. The two skills selected for this study were Pap smear and Intra Uterine Contraceptive Device (IUCD) insertion. The acquired data were analyzed by descriptive statistics (frequency, percent and mean). Results: The results showed that student's initial mean score was 4/9, which increased to nearly $8 / 9$ in third attempt. Practically, all faculty members and students believed that DOPS was effective in facilitating students learning. Some of the students thought that repeated exposure to DOPS reduced their level of stress. Conclusions: It may be stated that DOPS is effective in facilitating students' learning and clinical skills.
\end{abstract}

Keywords: Assessment; DOPS; Learning; Obstetrics and Gynecology; WPBA.

\section{INTRODUCTION}

Mastering of clinical skills is central to postgraduate medical education training. In the last decade, postgraduate training has adopted a paradigm shift by migrating from purely knowledge based to competency-based training where the anticipated outcomes are predefined ${ }^{1}$.

Assessment is an indispensable component of education for the improvement of quality of education including the clinical skills of the students. This is important in facilitating students to acquire clinical skills as postgraduate students ${ }^{2}$. This function of assessment is hardly used because of various reasons and practically $50 \%$ of students are not observed while performing clinical examination ${ }^{3}$. Other reports also suggest that during the training period less than one-third of clinical encounters are observed $^{4}$. Moreover, even at postgraduate level, students do not receive any useful comments and feedback $80 \%$ of the time 5 .

Therefore, work place based assessment (WPBA) which is defined as 'assessment of working practices based on what student is undertaking in workplace is getting more established ${ }^{6}$. WPBA also helps in gathering both quantitative and qualitative data about student's performance. This collected information can

Corresponding author:

Karma Tenzin

karmatenzin9@gmail.com be used for providing productive feedback to the student, thus enabling learning as well as assessing at the same time.

Direct observation of Procedural Skills (DOPS) is one of the WPBA tools, which permits direct observation of the student in a real-life setting while performing actual tasks and allows the assessor to provide the feedback immediately ${ }^{7}$ The main purpose of DOPS is to provide formative assessment and feedback about performance of the student. In spite of evidence in promoting learning with the use of feedback based on observation of performance, DOPS is often not well utilized in medical education ${ }^{8,9}$.

In Bhutan, there is no evidence available on the role of DOPS on student assessment.

Along similar lines, postgraduate students at the Department of Obstetrics and Gynaecology at the Faculty of Postgraduate Medicine, Khesar Gyalpo University of Medical Sciences (KGUMSB), did not get evaluated for their clinical skills in the existing system. Therefore, both the faculty and students of Department of Obstetrics and Gynaecology were introduced to DOPS.

The purpose of this study was to assess the effect of formative evaluation using DOPS on the learning of postgraduate students in the Department of Obstetrics and Gynaecology. It is also aimed at recording the perception of both the faculty members and students regarding DOPS. Reflections of the students on DOPS encounters were also recorded. 


\section{METHODS}

\section{Study design, site and period}

The study was a sequential mixed method study. The Research Ethics Board of Health provided ethical approval for the study (Ref. No. REBH/PO/2018/047, dated: $19^{\text {th }}$ July 2018). The study was conducted at Gynaecology outpatient department (OPD) at Jigme Dorji Wangchuck National Referral Hospital in Thimphu from August 2018 to March 2019. Written informed consent was obtained from all participants of the study.

\section{Study population and sample size}

All five postgraduate students in the Department of Obstetrics and Gynaecology were enrolled for the study after getting informed written consent. All four faculty members of the Department were also enrolled as assessors of DOPS.

Sensitization and selection of clinical skills for the study A half a day workshop was organized for both the faculty and postgraduate students of Department of Obstetrics and Gynaecology to introduce DOPS. All the participants (both faculty and students) agreed to utilize the existing standard operative procedure in the Department \& DOPS checklist that was adopted by the faculty. The predetermined core areas as incorporated in our PG curriculum were included ${ }^{9}$. The areas of assessment included were;

- Consent

- Preparation

- Infection control

- Technical ability

- Patient interaction

This was followed by a brain storming session among the faculty members and principal investigator on how many skills and which ones to be used for this study. The two most commonly performed procedures in Gynaecology OPD were Pap smear and IUCD insertion, however postgraduate students were not performing them till date due to shortage of staffs in other sections. Therefore, it was agreed through consensus to adopt these two procedures for this study.

\section{Steps in data collection}

Firstly, the students were given lectures and demonstration on performing Pap smear and IUCD insertion by the Head of the Department which was followed by PG students' performance with DOPS.

Secondly, it was mutually agreed among postgraduate students that they would prefer an alphabetical order on who should be assessed first. However, for the faculty members, Head of the Department, decided that first month faculty A will assess the postgraduate student, followed faculty B in the subsequent month, faculty $\mathrm{C}$ on third month and lastly by faculty $\mathrm{D}$.

Each student performed the Pap smear and IUCD insertion at Gynaecology OPD with faculty A on first week of the month. The routine was strictly followed but day for performing the procedure was not fixed since it was practically not possible due to nature of clinics set up. Soon after completion of each DOPS, the student received feedback from the faculty (assessor). This was conducted in a conducive and friendly environment in a separate room away from patients and other health professionals. At the end, each student was given time to reflect on DOPS and make a note. The student performed both the procedures on same day with the same faculty. The total duration that was required for both DOPS was around 1 hour. The principal investigator sat through the session initially to assist with correct implementation of DOPS and feedback practices, but later was only an observer of the session. A questionnaire consisting of simple YES or NO questions were used to gather perception of faculties and students about DOPS.

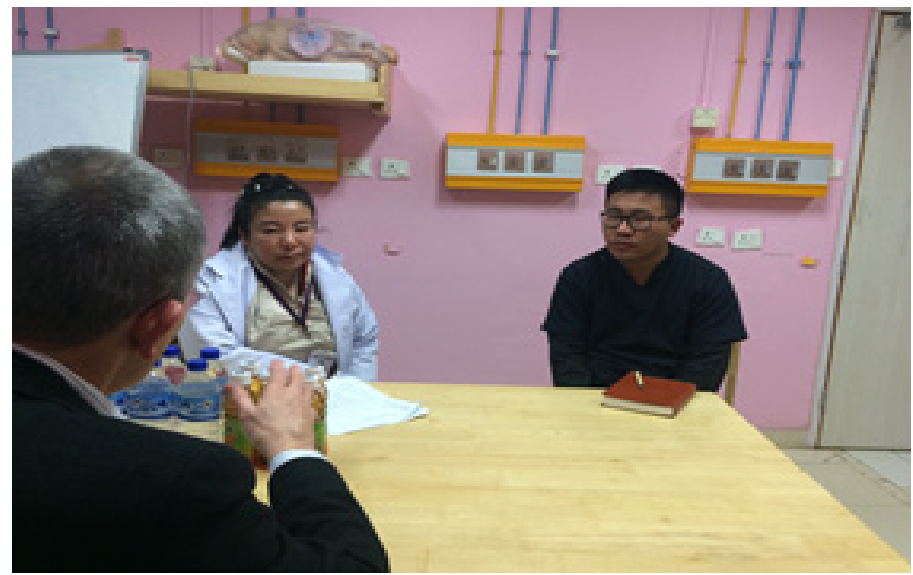

Figure 1. Training on giving and receiving feedback

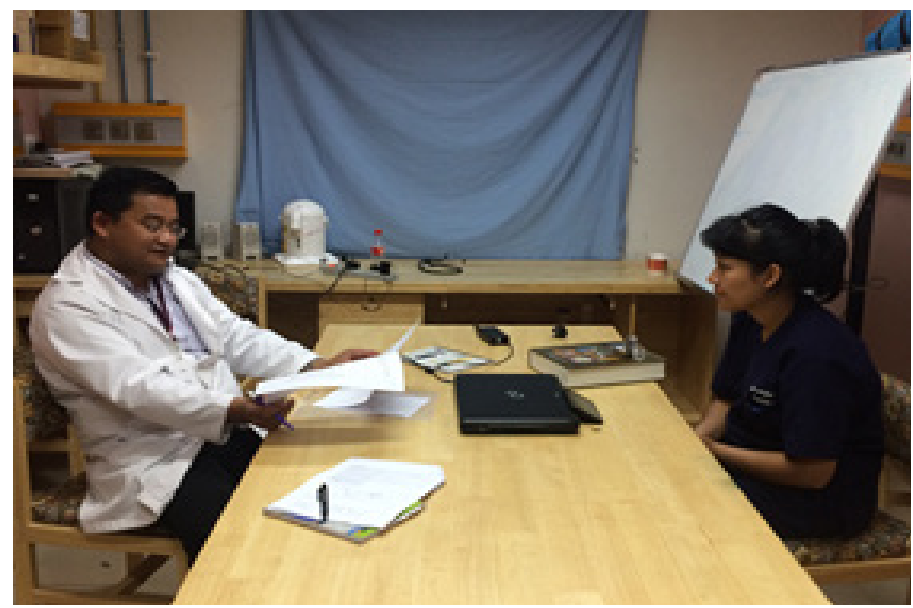

Figure 2. Assessor giving feedback to student

\section{RESULTS}

A total of five postgraduate students of the Department of Obstetrics and Gynecology were enrolled in this study with four faculty members as assessors. The average mean score for both Pap smear and IUCD insertion was around 4 on first session. Of the identified 5 areas of assessment, technical ability for Pap smear was 3.6 out of 9 and technical ability for IUCD insertion 
was 3.0 out of 9. For both Pap smear and IUCD insertion, students average high for patient consent at nearly 4 of 9 in first attempt. In the fourth attempt, all the five identified areas of assessment had an average of nearly 8 out of 9 (Figure 3 and Figure 4).

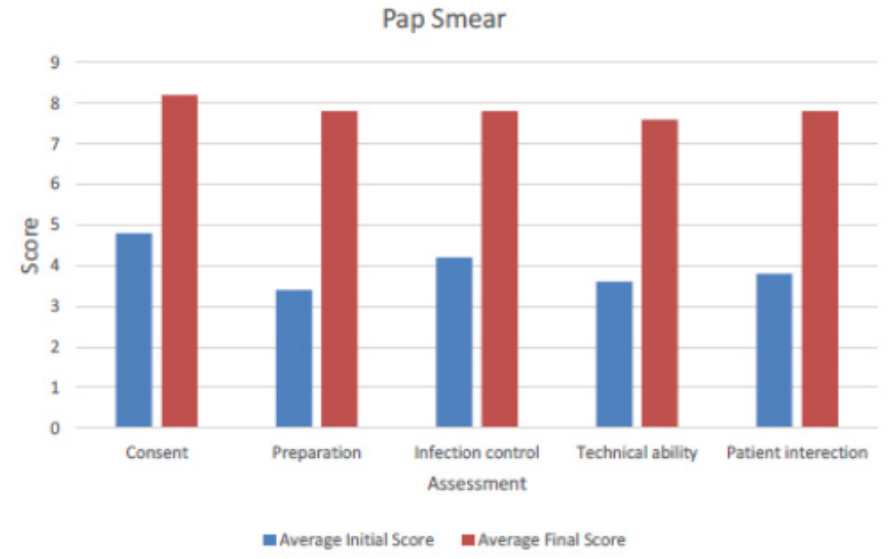

Figure 3. Comparison of student performance in first and fourth encounter of DOPS on Pap smear

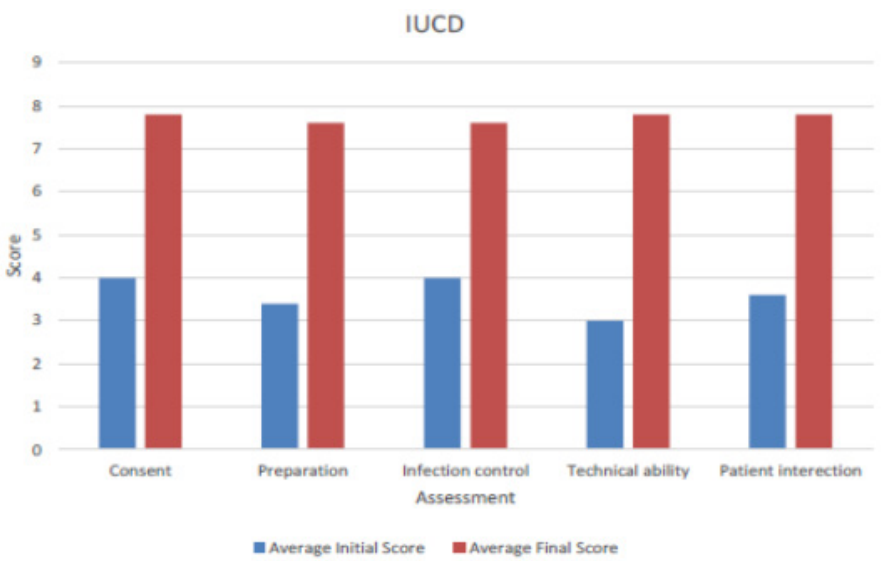

Figure 4. Comparison of student performance in first and fourth encounter of DOPS on IUCD insertion

The study clearly demonstrates that repeated encounters to DOPS produced an overall improvement of student's scores. The average scores of fourth DOPS encounter shows a significant visible difference in comparison to first DOPS encounter in all five areas of assessment. This is indicative that repeated DOPS encounter results in improvement of skills and confidence of the students in performing all the five steps efficiently. This reflects that when students were made to perform the same task repeatedly under observation, their skills, knowledge and confidence improved. Every DOPS attempt was followed by a feedback session where the faculty shared "what went well to reinforce the good quality in a student and to keep what is good. Next was "what could be done differently", here the faculty put up areas of improvement to be adopted during the in next attempt in an appropriate language. The mean pre-feedback score for both Pap smear and IUCD insertion was estimated at 3.9/9. However, the mean score improved by nearly 4 after final encounter as seen in Figure 1 and 2. At the end of all fourth attempts, both faculty members and students shared their perception on DOPS as depicted in Table 1 and 2.

This study also recorded the reflections of students on DOPS encounters. The reflections were categorized under two themes, DOPS as learning tool and as an assessment tool as shown in Box 01.

Table 1. Perception of Obstetrics and Gynaecology students regarding DOPS

\begin{tabular}{lll}
\hline Sl. no & Statements & Agree or Disagree \\
\hline 1. & Adequate amount of time was given for exercise & $5 / 5(100 \%)$ agreed \\
2. & Constructive feedback was provided in a non-threatening & $5 / 5(100 \%)$ agreed \\
& way. & \\
3. & Being observed did not affect my performance. & $5 / 5(100 \%)$ agreed \\
4. & It was good idea to be assessed by many assessors & $5 / 5(100 \%)$ agreed \\
5. & There is improvement in clinical skills and confidence & $5 / 5(100 \%)$ agreed \\
& after undergoing subsequent assessments & \\
6. & It was good idea to incorporate DOPS in PG curriculum & $5 / 5(100 \%)$ agreed
\end{tabular}

Table 2. Perception of Obstetrics and Gynaecology faculty regarding DOPS

\begin{tabular}{lll}
\hline Sl. no & Statements & Agree or Disagree \\
\hline 1. & Easy to carry out & $4 / 4(100 \%)$ agreed \\
2. & $\begin{array}{l}\text { Does not require more time or } \\
\text { commitment }\end{array}$ & $4 / 4(100 \%)$ agreed \\
3. & $\quad \begin{array}{l}\text { Can supplement but cannot replace } \\
\text { traditional case presentation }\end{array}$ & $4 / 4(100 \%)$ agreed \\
4 & $\quad \begin{array}{l}\text { It involves too much paper work for a } \\
\text { busy clinician }\end{array}$ & $0 / 4(100 \%)$ disagreed \\
& $\begin{array}{l}\text { It was good idea to incorporate DOPS in } \\
\text { PG curriculum }\end{array}$ & $4 / 4(100 \%)$ agreed
\end{tabular}

DOPS as method for learning
'Useful because the small things were overlooked, especially when
doing a procedure'
'I'm benefited by doing DOPS; as I performed in front of an
observer that gives me a sense of learning
appropriately'
'I was very nervous; when doing first time'
'I enjoyed the feedback, because I became aware of my
shortcomings and how to correct them'
DOPS as method of assessment
'Good method of assessment with immediate feedback and
correction'
Improves communication and interaction with patient'
'I felt nervous while performing under observation'

Box 01. Themes generated by analysis of reflection by students on procedure and learning 


\section{DISCUSSION}

The main finding from this study is that both the faculty and students appreciated that the DOPS to be useful learning as well as assessment tool. So DOPS is an effective tool for learning as well as assessment of postgraduate students in Department of Obstetrics and Gynaecology. They reported that DOPS encounters facilitates learning as well as clinical performance. This is true as reported in many literature ${ }^{1,10}$.

Learning in postgraduate education encapsulates not only cognitive, attitude and psychomotor skills but also the reactiveness and appropriate actions in real life situations in real time. There are many literature that reports that these outcomes do not get measured in the traditional system of assessment such as long and short cases, where the environment is controlled during examination ${ }^{11}$.

Hence it is always appropriate to evaluate the postgraduate students in real life situations and in work place. WPBA is one such tool that is being increasingly used for assessment ${ }^{12}$.

\section{Mean scores of DOPS}

The results of this study showed that, generally, there is an increasing trend in average score from the first attempt to the third stage, but the mean score of third and fourth attempts remained nearly the same. This is similar to the findings by other studies in the region ${ }^{13,14}$.

\section{Feedback Session}

All the participants expressed that introduction to DOPS had positive influence on their learning. Similarly in several other studies, students accepted the educational value of WPBA tools ${ }^{15-17}$. On closer examination, students appreciated that receiving positive feedback was the most significant part ofDOPS assessment. One of the student wrote this in reflection "I enjoyed the feedback, because I became aware of my shortcomings and how to correct them". Although our understanding about DOPS is limited, various studies from other countries suggest that students enjoy receiving constructive feedback on their performance ${ }^{18}$. However, there is a necessity to train the assessors on feedback skills as some assessors gave only negative feedback.

\section{Perception}

All four faculty members and students believed that DOPS was effective in facilitating learning. Some of the students thought that repeated exposure to DOPS reduced their level of stress. Nearly all faculty members and postgraduate students expressed that appropriate use of DOPS and timely feedback to students can have a great impact on promoting students' skill and competence.

\section{Student's reflection}

The analysis of reflections showed that DOPS was appreciated as a useful learning as well as an assessment tool. Student's reflection on DOPS as a learning tool: "I'm benefited by doing
DOPS; as I performed in front of an observer that gives me a sense of learning appropriately". DOPS as assessment tool: "good method of assessment with immediate feedback and correction".

\section{Strengths of the study}

This is a first study of its kind in the country; a sequential mixed method study that is exploring the appropriateness of DOPS for learning as well as an assessment tool.

Not only does this study explored the perception of teachers and learners, it also looked into the reflections by postgraduate students on their experience with DOPS.

\section{Limitations of the study}

The external validity and ability to generalize the findings of this study may not be possible due to small sample size. Perceptions of postgraduate students of Obstetrics and Gynaecology may not be generalizable to other categories of postgraduate students.

\section{CONCLUSIONS}

It can be stated the DOPS is an appropriate tool for learning as well for assessment in postgraduate students of Obstetrics and Gynaecology at KGUMSB. DOPS promotes students' procedural skills and improves independence during the procedure ${ }^{15}$.

\section{ACKNOWLEDGEMENTS}

The authors would like to express deepest gratitude to all the Postgraduate students of Department of Obstetrics and Gynaecology, KGUMSB for their support. We also would like to express gratitude to Dean and other senior management at KGUMSB for their support.

\section{REFERENCES}

1. Kumar N, Singh NK, Rudra S, Pathak S. Effect of formative evaluation using direct observation of procedural skills in assessment of postgraduate students of obstetrics and gynecology: Prospective study. Adv Med Educ Prof. 2017 Jan; 5(1): 1-5. [PubMed | Full Text]

2. Singh T, Sood R. Workplace-based assessment: measuring and shaping clinical learning. Natl Med J India. 2013;26(1):42-6. [Full Text]

3. Association of American Medical Colleges. Medical school graduation questionnaire: All schools report. Washington, DC: AAMC; 2018. [Full Text]

4. Daelmans HE, Hoogenboom RJ, Donker AJ, Scherpbier AJ, Stehouwer CD, Van der Vleuten CP. Effectiveness of clinical rotations as a learning environment for achieving competences. Med Teach. 2004;26(4):305-12. [Full Text | $\mathrm{DOI}]$

5. Isaacson JH, Posk LK, Litaker DG, Halperin AK. Students' perceptions of the evaluation process. J Gen Intern Med. 1995; 10(Suppl):89. 
6. Liu. C. An introduction to work place-based assessments. Gastroentrol Hepatol Bed Bench 2012;5(1): 24-8. [PubMed [ Full Text]

7. Govaerts MJ, Van der Vleuten CP, Schuwirth LW, Muijtjens AM. Broadening perspectives on clinical performance assessment: rethinking the nature of in-training assessment. Adv Health Sci Educ Theory Pract. 2007;12(2):239-60. [Full Text | DOI]

8. Eralil G J. Role of structured feedback of direct observation of procedural skills in improving clinical skills in interns. Journal of Postgradaute Medicine, Eduation and Research. 2017;51(1):22-7. [Full Text | DOI]

9. Kundra S, Singh T. Feasibility and acceptability of direct observation of procedural skills to improved procedural skills. Indian Pediatr. 2014;51(1):59-60. [PubMed | DOI]

10. Wiles CM, Dawson K, Hughes TA, Llewelyn JG, Morris HR, Pickersgill TP, et al. Clinical skills evaluation of students in a neurology department. Clin Med (Lond). 2007;7(4):365-9. [PubMed | Full Text | DOI]

11. Kogan JR, Hauer KE. Brief report: Use of the miniclinical evaluation exercise in internal medicine core clerkships. J Gen Intern Med. 2006;21(5):501-2. [Full Text | DOI]

12. Bazrafkan L, Shokrpour N, Torabi K. Comparison of the Assessment of Dental Students. Journal of Medical Education 2009;13(1,2):16-23. [Full Text]

13. Amini A, Shirzad F, Mohseni MA, Sadegpour A, Emli A. Designing Direct Observation of Procedural Skills (DOPS) Test for Selective Skills of Orthopedic Residents and Evaluating Its Effects from Their Points of View. Res Dev Med Educ. 2015;4(2):147-52. [Full Text | DOI]
14. Akbari M, Shamsabadi RM. Direct Observation of Procedural Skills (DOPS) in Restorative Dentistry: Advantages and Disadvantages in Student's Point of View. Iranian Journal of Medical Education. 2013;13(3):212-20. [Full Text]

15. Dhole A. Assessment of Post Graduates (PG) for Extra Oral Radiograph Techniques by DOPS (Direct Observation of Procedural Skills) Method. Journal of Research \& Method in Education. 2017; 7(1): 7-9. [Full Text | DOI]

16. Waqar S.H. students' perception of direct observation of procedural skills as workplace based assessment tool in general surgery. Pak Armed Forces Med J. 2016;66(5):7317. [Full Text]

17. Sande S. Direct Observation of Procedural Skills as an Assessment Tool for Postgraduates in Medical Microbiology. International Journal of Health Sciences \& Research. 2017; 7(2): 56-62. [Full Text]

18. Shahgheibi S, Pooladi A, Bahramrezaie M, Farhadifar F, Khatibi R. Evaluation of the effect of direct observation of procedural skill (DOPS) on clinical externship students learning level in obstetrics ward of Kurdistan university of medical sciences. J Med Educ. 2009; 13:29-33. [Full Text]

\section{AUTHORS CONTRIBUTION}

Following authors have made substantial contributions to the manuscript as under:

KT: Concept, design, data collection and analysis, manuscript writing and review.

SG: Design, data collection and analysis, manuscript writing and review

TW: Design, data collection, manuscript writing and review

PCB: Design, data collection, manuscript writing and review

LC: Design, data collection, manuscript writing and review

NR: Design, data collection, manuscript writing and review

Author agree to be accountable for all respects of the work in ensuring that questions related to the accuracy and integrity of any part of the work are appropriately investigated and resolved.

\section{CONFLICT OF INTEREST}

None

GRANT SUPPORT AND FINANCIAL DISCLOSURE

None 